\title{
Controle genético da resistência aos enfezamentos do milho(1)
}

\author{
Ricardo Gonçalves Silva(2), João Carlos Cardoso Galvão ${ }^{(3)}$, Glauco Vieira Miranda ${ }^{(3)}$ e Elizabeth de Oliveira ${ }^{(4)}$
}

Resumo - O objetivo deste trabalho foi identificar o controle genético da resistência aos enfezamentos do milho (Zea mays L.). Foram realizados dois experimentos em março de 2001 nos municípios de Coimbra e Sete Lagoas, em Minas Gerias. Cada experimento foi constituído por 25 tratamentos, dos quais cinco foram representados pelos híbridos e os demais pelas combinações híbridas e suas recíprocas. Utilizou-se o delineamento em blocos ao acaso, com três repetições. A parcela experimental foi aproveitada integralmente, constituindo-se de duas linhas com $5 \mathrm{~m}$ de comprimento e espaçamento de $0,9 \mathrm{~m}$, com 25 plantas por linha, representando uma população de aproximadamente 55.000 plantas por hectare. Na época do enchimento dos grãos realizaram-se as avaliações de incidência e severidade dos enfezamentos. Utilizou-se, ainda, o índice de doença. Nos dois locais, foram avaliadas as produções de grãos de milho em cada parcela. Em virtude de o método baseado na incidência dos sintomas apresentar alta herdabilidade, foi possível confirmar sua eficiência. Os alelos com efeitos predominantemente aditivos controlam a resistência do milho aos enfezamentos; os genitores diferiram quanto à freqüência de alelos aditivos e não-aditivos para resistência aos enfezamentos.

Termos para indexação: Zea mays, híbrido, genitores, capacidade combinatória.

\section{Genetic control of the resistance to corn stunt}

\begin{abstract}
The objective of this work was to identify the genetic control of the resistance to corn (Zea mays L.) stunt. Two experiments were set up at March 2001, in Coimbra and Sete Lagoas, Minas Gerais State, Brazil. Each experiment consisted of 25 treatments, five of them were represented by maize hybrids. Other treatments were the hybrid combinations and their reciprocal ones. The randomized blocks design with three replicates was used. The experimental plot was integrally used and consisted of two $5 \mathrm{~m}$ rows at a $0.9 \mathrm{~m}$ spacing from each other, with 25 plants per row,

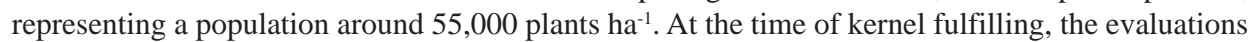
were performed for incidence and severity of the corn stunt. The disease index was also used. In both places, the productivity of the maize kernels were evaluated for each plot. Therefore, since this method presents high heritability it was possible to confirm its efficiency. The genetic control of the resistance to corn stunt is mainly controlled by the alleles with predominant addictive effects; the parents differed in relation to the frequency of the addictive and nonaddictive alleles for resistance to corn stunt.
\end{abstract}

Index terms: Zea mays, hybrid, parents, combining ability.

(1) Aceito para publicação em 22 de abril de 2003.

Extraído da dissertação de mestrado apresentada pelo primeiro autor à Universidade Federal de Viçosa (UFV), Viçosa, MG.

(2) UFV, Dep. de Genética e Melhoramento, Avenida P. H. Rolfs, s/no, CEP 36570-000 Viçosa MG.

E-mail: rgoncalves@tdnet.com.br

(3) UFV, Dep. de Fitotecnia. E-mail: jgalvao@ufv.br, glauco@ufv.br

(4) Embrapa-Centro Nacional de Pesquisa de Milho e Sorgo, Caixa Postal 151, CEP 35701-970 Sete Lagoas, MG.

E-mail: beth@cnpms.embrapa.br

\section{Introdução}

Os enfezamentos vermelho e pálido causados por molicutes, isto é, fitoplasma e espiroplasma, respectivamente, são doenças causadoras de sérios prejuízos econômicos à cultura do milho. A essas doenças foi dada especial atenção por causa da alta incidência, da suscetibilidade da maioria dos híbridos comerciais de milho e dos prejuízos que podem causar à produção nas regiões onde o plantio safrinha é realizado. No Estado do Paraná, a perda causada pelos 
enfezamentos no milho safrinha foi estimada em cerca de US\$ 40 milhões (Silva, 2002). No Brasil, os agentes causais dos enfezamentos são transmitidos pela cigarrinha Dalbulus maidis (Oliveira, C. et al., 2002).

Entretanto, observa-se que surtos dessas doenças têm ocorrido apenas em anos recentes, havendo, por isso, carência de informações sobre o comportamento da maioria dos híbridos comerciais de milho atualmente disponíveis no mercado (Oliveira, E. et al., 2002).

Variabilidade genética de resistência em híbridos tem sido relatada em trabalhos de avaliação de cultivares (Basso, 1999), ou pelas próprias empresas produtoras de sementes. O emprego de cultivares com resistência genética constitui, atualmente, a alternativa mais eficiente para controle dos enfezamentos. Contudo, além de fontes de resistência que possibilitem a síntese de novas cultivares, o desenvolvimento de cultivares resistentes requer o conhecimento sobre a herança dos caracteres envolvidos na seleção, permitindo, assim, a utilização de métodos mais eficientes para a seleção em um programa de melhoramento (Basso, 1999).

Estudos realizados com germoplasma de clima temperado revelaram que a herança da resistência é de natureza quantitativa (Márquez Sánchez, 1982) e que os efeitos genéticos aditivos são predominantes para a característica de resistência aos enfezamentos (Grogan \& Rosenkranz, 1968; Nelson \& Scott, 1973).

Nos programas de melhoramento, entre os delineamentos genéticos utilizados para determinar os tipos de ação gênica que controlam os caracteres quantitativos encontram-se os cruzamentos dialélicos (Griffing, 1956). A análise dialélica estima os parâmetros genéticos para a seleção de genitores para hibridação (Cruz \& Regazzi, 1997).
O objetivo deste trabalho foi identificar o controle genético da resistência aos enfezamentos do milho.

\section{Material e Métodos}

Utilizaram-se os híbridos comerciais AG 122, C 333B, C 855, P 3041 e P 30F80, cujas principais características agronômicas, considerando-se informações fornecidas pelas empresas produtoras das sementes e observações no campo referentes à resistência aos enfezamentos, são apresentadas na Tabela 1. Os cinco genitores foram cruzados entre si em esquema dialélico, obtendo-se as combinações híbridas e recíprocas, as quais foram avaliadas quanto à resistência aos enfezamentos, no campo. Cada experimento consistiu de 25 tratamentos, representados pelos cinco híbridos comerciais, 10 combinações híbridas e 10 recíprocas.

Os experimentos foram instalados no mês de março de 2001 na Estação Experimental de Coimbra, pertencente à Universidade Federal de Viçosa (UFV), no Município de Coimbra, MG, na latitude de $20^{\circ} 45^{\prime} \mathrm{S}$, longitude de $42^{\circ} 51^{\prime} \mathrm{W}$ e altitude de 720 m, e na Embrapa-Centro Nacional de Pesquisa de Milho e Sorgo (CNPMS), no Município de Sete Lagoas, MG, com $19^{\circ} 28^{\prime} \mathrm{S}$ de latitude, $44^{\circ} 15^{\prime} 8^{\prime \prime} \mathrm{W}$ de longitude e altitude de $732 \mathrm{~m}$.

Os locais foram escolhidos por apresentarem na época de semeadura alta densidade de cigarrinhas Dalbulus maidis, que é o vetor dos agentes causais dos enfezamentos (Waquil \& Fernandes, 1994; Silva et al., 2002).

Utilizou-se o delineamento experimental em blocos casualizados, com três repetições. A parcela experimental foi aproveitada, integralmente, sendo constituída de duas linhas de 5,0 m de comprimento, espaçadas de $0,9 \mathrm{~m}$, com 25 plantas por linha, constituindo população de aproximadamente 55.000 plantas por hectare.

Por ocasião da semeadura, na estação Experimental de Coimbra, aplicaram-se $500 \mathrm{~kg} / \mathrm{ha}$ da fórmula 4-14-8 e na Embrapa-CNPMS, $350 \mathrm{~kg} / \mathrm{ha}$ da fórmula 5-20-20 + zinco.

A adubação nitrogenada ( $200 \mathrm{~kg} / \mathrm{ha}$ de sulfato de amônio) aplicada em cobertura, nos dois locais, foi realizada no estádio fenológico 2, correspondente a quatro folhas completamente desenvolvidas (Fancelli \& Dourado-Neto, 2000).

Tabela 1. Principais características agronômicas dos genitores utilizados nos cruzamentos dialélicos de milho ${ }^{(1)}$.

\begin{tabular}{llllll}
\hline Genitores & Híbrido & Ciclo & Tipo de grãos & Enfezamentos & Plantio \\
\hline AG 122 & Duplo & Precoce & Am/Semident & MS & Safrinha \\
C 333B & Simples mod. & Normal & Am/Semiduro & Resistente & Safrinha \\
C 855 & Triplo & Superprecoce & Am/Semident & Suscetível & Safrinha \\
P 3041 & Triplo & Precoce & Al/Duro & Resistente & Tardio \\
P 30F80 & Simples & Semiprecoce & Al/Duro & MR & Safrinha \\
\hline
\end{tabular}

(1)Am: amarelo; Al: alaranjado; MS: moderadamente suscetível; MR: moderadamente resistente. 
Em ambos os locais, durante o cultivo, foram realizados o controle de plantas daninhas, por meio de capinas manuais e irrigação suplementar. O controle da lagarta-docartucho (Spodoptera frugiperda) foi realizado somente na Embrapa-CNPMS.

$\mathrm{Na}$ Estação Experimental de Coimbra, o experimento foi instalado próximo a áreas onde havia semeadura de milho comum e pipoca. Na Embrapa-CNPMS, o experimento foi instalado próximo a um experimento de épocas de plantio de variedade de milho pipoca. Esse cuidado foi tomado para garantir a presença dos agentes causais dos enfezamentos e do inseto-vetor, a cigarrinha Dalbulus maidis.

Aos 25 dias após emergência, foi estimada, visualmente, a população da cigarrinha nas áreas experimentais. $\mathrm{Na}$ época de enchimento dos grãos, no estádio fenológico 7 , correspondente ao grão leitoso (Fancelli \& Dourado-Neto, 2000), realizaram-se as avaliações de incidência e severidade dos sintomas de enfezamentos. Essas avaliações foram realizadas pelo mesmo avaliador, sem identificação prévia dos tratamentos.

A incidência de enfezamentos foi determinada com base no porcentual de plantas com sintomas da doença. A severidade dos sintomas foi determinada atribuindo-se notas de 1 a 6 , referentes à média dos sintomas das plantas na parcela, em que 1: ausência de sintomas; 2 : plantas com menos de $25 \%$ das folhas com sintomas, ou seja, folha avermelhada ou amarelada, ou apresentando faixas cloróticas em sua inserção; 3: plantas com $25 \%$ a $50 \%$ das folhas com sintomas; 4 : plantas com $50 \%$ a $75 \%$ das folhas com sintomas; 5: plantas com mais de $75 \%$ das folhas com sintomas e 6: plantas com morte precoce causada por enfezamentos.

Utilizou-se, ainda, o índice de doença (ID) determinado pela fórmula de Mckney (1923), citada por Tanaka (1990), dada pela expressão:

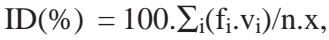

em que $\mathrm{f}_{\mathrm{i}}$ é o número de plantas com a mesma nota; $\mathrm{v}_{\mathrm{i}}$ é a nota observada; $\mathrm{n}$ é o número total de plantas avaliadas e $\mathrm{x}$ é a nota máxima da escala.

Em cada experimento coletaram-se, aleatoriamente, 15 amostras da folha apical, ou bandeira das plantas, com sintomas dos enfezamentos, para detecção dos molicutes (espiroplasma e fitoplasma). A detecção desses patógenos foi realizada por meio de testes PCR multiplex, utilizando-se, para detecção de fitoplasma, os iniciadores (primers) R16F2: 5' - ACG ACT GCT GCT AAG ACT GG - 3' e R16R2: 5' - TGA CGG GCG GTG GTA CAA ACC GCG - 3' (Lee et al., 1993) e, para detecção de espiroplasma, os iniciadores (primers) CSSF2: 5'- GGC AAA AGA TGT AAC AAA AGT - 3' e CSSR6: 5'- GTT TAC TTC AAC AGT AGT TGC G - 3' (Barros et al.,
2001). Foram utilizadas as condições de reação descritas por Lee et al. (1993). Os resultados do PCR multiplex foram usados para determinar a predominância de espiroplasma ou fitoplasma.

A análise dialélica individual e conjunta foi realizada considerando-se o Modelo 1 (genótipos e ambientes aleatórios), seguindo o Método 1 proposto por Griffing (1956), com o auxílio do Programa Genes Versão Windows (Cruz, 2001).

\section{Resultados e Discussão}

Os sintomas predominantemente observados em ambos os locais foram de enfezamento pálido causado por espiroplasma. Em geral, as plantas apresentaram faixas esbranquiçadas na base das folhas, próximo à inserção do colmo, ou amarelecimento foliar, típicos de infecção por espiroplasma, e freqüentemente algum grau de avermelhamento, principalmente nas folhas apicais. Além dos sintomas foliares, as plantas apresentaram encurtamento dos internódios, crescimento reduzido e aspecto raquítico, corroborando com os sintomas descritos por Nault (1980).

A predominância de infecção por espiroplasma em relação ao fitoplasma em todos os experimentos foi confirmada pelo teste de PCR (Polymerase Chain Reaction) (Figura 1). Em Coimbra, das 15 amostras das folhas apicais coletadas, 10 apresentaram reações positivas aos molicutes e $70 \%$ delas foram positivas em relação ao espiroplasma. Em Sete Lagoas, $100 \%$ das nove amostras positivas, para os molicutes, foram positivas em relação ao espiroplasma. Algumas amostras de folhas com sintomas dos enfezamentos não apresentaram reação positiva aos molicutes. Resultado semelhante foi obtido por Oliveira et al. (1998), os quais atribuíram a dificuldade na detecção dos molicutes nas amostras de folhas apicais com sintomas de enfezamentos à distribuição desigual deles na planta.

Foi constatado efeito significativo em relação às fontes de variação: tratamentos x locais e capacidade geral de combinação (CGC) x locais (Tabela 2). Tal fato indica que os tratamentos e a CGC tiveram comportamentos diferenciados nos dois locais. Não foram identificados efeitos significativos quanto à capacidade específica de combinação (CEC), efeito recíproco (ER) e interação deles com os locais. Com rela- 
ção à característica índice de doença, constatou-se efeito significativo apenas quanto a CGC x locais. Em relação às demais características não se verificou nenhum efeito de interação entre as fontes de variação.

Os genitores apresentaram incidência média de enfezamentos de 22,22\%, já as combinações híbridas tiveram média de 19,78\% (Tabela 3). Os genitores P 3041 e C 333B proporcionaram as menores incidências e o genitor C 855 apresentou a maior incidência de plantas com sintomas dos enfezamentos. O P 30F80 e o AG 122 apresentaram incidência moderada. Os genitores P 3041 e C 333B produziram a combinação híbrida com menor incidência dos sintomas de enfezamentos. Os genitores C 333B e P 3041 apresentaram os menores valores negativos e significativos de CGC (-7,98 e -3,25, respectivamente). Esses dois genitores produziram combinações híbridas com as médias mais baixas de incidência, ou seja, 11,67\% e $16,47 \%$, revelando que os genitores com menor
CGC produzem combinações híbridas com menores incidências dos sintomas dos enfezamentos. O C 855 apresentou a maior CGC e, conseqüentemente, a média de suas combinações híbridas foi alta (24,75\%). Neste experimento, o P 30F80 e o AG 122 comportaram-se de maneira semelhante. A CGC e a média das combinações híbridas foram próximas.

Em Sete Lagoas, os genitores e as combinações híbridas apresentaram incidência média de enfezamentos de $26,73 \%$ e $20,13 \%$, respectivamente (Tabela 3). Os genitores C 855 e AG 122 revelaram as maiores incidências dos sintomas de enfezamentos, enquanto as menores incidências ficaram por conta dos genitores $\mathrm{P} 3041$ e C 333B. O genitor P 30F80 teve incidência moderada. Os genitores C 333B e P 3041 apresentaram os valores mais negativos de CGC (-9,77 e -7,67, respectivamente). Esses dois genitores produziram combinações híbridas com as médias mais baixas de incidência, respectivamente $12,70 \%$ e

\section{Coimbra}

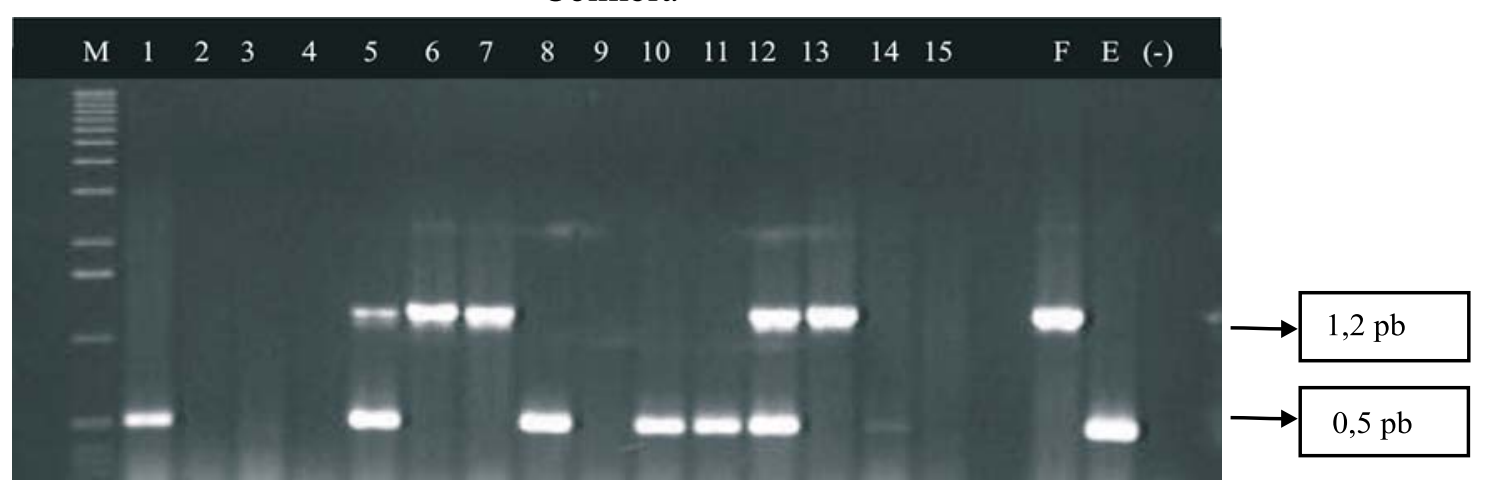

Sete Lagoas

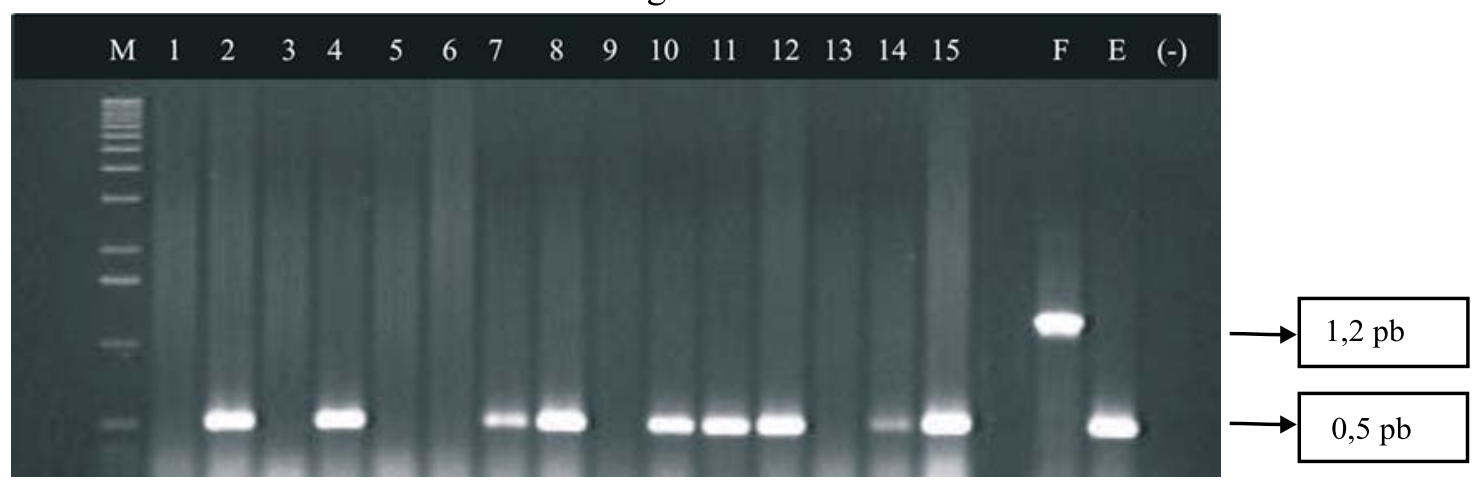

Figura 1. Resultados de PCR multiplex para a detecção de fitoplasma e espiroplasma, agentes causais dos enfezamentos vermelho e pálido, respectivamente, em Coimbra, MG, e Sete Lagoas, MG; M: marcador; F: fitoplasma; E: espiroplasma e (-) controle negativo. Os números à direita indicados pelas flechas representam o número de pares de bases. 
$15,52 \%$, confirmando que genitores com menor CGC produzem combinações híbridas com menores incidências dos sintomas de enfezamentos. Os genitores C 855 e AG 122 apresentaram maiores CGC e, conseqüentemente, a média de suas combinações híbridas foram altas (25,05\% e 25,71\%, respectivamente).

A significância da interação CGC $x$ locais, em relação à incidência, foi determinada em razão do genitor
AG 122, que apresentou alta variação na CGC. O seu comportamento, nos dois locais, talvez esteja relacionado ao ambiente em razão da maior expressão dos sintomas de enfezamentos em Sete Lagoas, causada pela alta temperatura média diária registrada durante o período que propicia rápido desenvolvimento dos patógenos causadores dos enfezamentos e, conseqüentemente, maior expressão dos sintomas

Tabela 2. Análise dialélica conjunta para incidência (INC), índice de doença (ID) e severidade (SEV) dos sintomas de enfezamentos e produtividade de grãos (PG) avaliados em híbridos de milho na safrinha de 2001, em Coimbra e Sete Lagoas, MG.

\begin{tabular}{lrcccc}
\hline Fonte de variação $^{(1)}$ & GL & \multicolumn{4}{c}{ Quadrado médio } \\
\cline { 3 - 5 } & & INC & ID & SEV & PG \\
\hline Tratamento (T) & 24 & $379,72^{* *}$ & $314,53^{* *}$ & $6,03^{* *}$ & $1,81^{\text {ns }}$ \\
CGC & 4 & $1.997,56^{*}$ & $1.595,23^{* *}$ & $15,98^{*}$ & $3,88^{\text {ns }}$ \\
CEC & 10 & $89,55^{\text {ns }}$ & $71,91^{\text {ns }}$ & $4,08^{\text {ns }}$ & $1,28^{\text {ns }}$ \\
ER & 10 & $22,76^{\text {ns }}$ & $44,86^{\text {ns }}$ & $4,00^{\text {ns }}$ & $1,52^{\text {ns }}$ \\
Local (L) & 1 & 149,52 & 66,71 & 3,99 & 45,36 \\
T x L & 24 & $70,66^{*}$ & $58,58^{\text {ns }}$ & $2,30^{\text {ns }}$ & $1,08^{\text {ns }}$ \\
CGC x L & 4 & $254,57^{* *}$ & $148,78^{* *}$ & $2,24^{\text {ns }}$ & $1,84^{\text {ns }}$ \\
CEC x L & 10 & $33,89^{\text {ns }}$ & $42,72^{\text {ns }}$ & $3,18^{\text {ns }}$ & $1,17^{\text {ns }}$ \\
ER x L & 10 & $33,87^{\text {ns }}$ & $38,37^{\text {ns }}$ & $1,45^{\text {ns }}$ & $0,69^{\text {ns }}$ \\
Resíduo & 96 & 39,22 & 39,55 & 2,38 & 0,74 \\
\hline $\mathrm{h}^{2}(\%)$ & & 89,68 & 87,43 & 60,57 & 59,00 \\
\hline CVe $(\%)$ & & 24,95 & 31,53 & 14,01 & 14,13 \\
\hline
\end{tabular}

${ }^{(1)}$ CGC: capacidade geral de combinação; CEC: capacidade específica de combinação; ER: efeito recíproco. ns Não-significativo. * e **Significativo a $5 \%$ e a $1 \%$ de probabilidade, respectivamente.

Tabela 3. Médias da incidência dos sintomas de enfezamentos (acima da diagonal) e estimativas da capacidade geral (CGC) e capacidade específica (CEC) de combinação (abaixo da diagonal, entre parênteses), dos genitores e das combinações híbridas e médias das combinações híbridas de milho na safrinha de 2001 em Coimbra e em Sete Lagoas, MG.

\begin{tabular}{|c|c|c|c|c|c|c|}
\hline Genitores & AG 122 & P 3041 & P 30F80 & C 333B & C 855 & Média \\
\hline \multicolumn{7}{|c|}{ Coimbra } \\
\hline AG 122 & 15,29 & 18,39 & 38,27 & 12,31 & 23,32 & 23,08 \\
\hline P 3041 & $(4,62)$ & 8,23 & 14,93 & 6,00 & 26,55 & 16,47 \\
\hline P 30F80 & $(3,44)$ & $(1,43)$ & 11,10 & 8,90 & 29,68 & 22,95 \\
\hline C 333B & $(-0,11)$ & $(-0,84)$ & $(0,13)$ & 7,16 & 19,46 & 11,67 \\
\hline C 855 & $(-7,29)$ & $(-1,87)$ & $(-0,67)$ & $(-4,23)$ & 59,32 & 24,75 \\
\hline CGC & $-1,05$ & $-3,25$ & $-1,32$ & $-7,98$ & 13,60 & \\
\hline \multicolumn{7}{|c|}{ Sete Lagoas } \\
\hline AG 122 & 46,92 & 15,61 & 37,50 & 16,41 & 33,31 & 25,71 \\
\hline P 3041 & $(-6,67)$ & 6,85 & 15,51 & 7,66 & 23,30 & 15,52 \\
\hline P $30 F 80$ & $(7,36)$ & $(1,53)$ & 21,44 & 8,46 & 25,31 & 21,70 \\
\hline C $333 \mathrm{~B}$ & $(-3,77)$ & $(3,64)$ & $(-3,41)$ & 7,61 & 18,27 & 12,70 \\
\hline C 855 & $(-5,40)$ & $(0,76)$ & $(-5,09)$ & $(-2,16)$ & 50,84 & 25,05 \\
\hline CGC & 8,50 & $-7,67$ & 0,19 & $-9,77$ & 8,75 & \\
\hline
\end{tabular}


típicos das doenças, conforme descrito por Pinto et al. (1997). Outra possível causa seria a ocorrência, nos dois experimentos, da predominância de variantes genéticas de molicutes que, por causa da diferença de agressividade, teriam superado a resistência genética do AG 122.

Em Coimbra, os genitores foram classificados quanto à incidência dos sintomas de enfezamentos em suscetível (C 855), moderadamente resistentes (P 30F80 e AG 122) e em resistentes (P 3041 e C 333B). Em Sete Lagoas, C 855 e AG 122 foram classificados como suscetíveis, P 30F80, como moderadamente resistente e P 3041 e C 333B, como resistentes.

A combinação híbrida e recíproca entre os resistentes apresentaram baixa incidência dos sintomas de enfezamentos. Entretanto, as combinações híbridas entre os resistentes x suscetíveis apresentaram incidência intermediária, o que indica que a resistência aos enfezamentos é controlada por mais de um gene, refletindo ausência de dominância. Esses resultados são semelhantes aos relatados por Nelson $\& \operatorname{Scott}(1973)$.

Com base nos resultados obtidos, é possível constatar que os genitores $\mathrm{P} 3041$ e C 333B possuem alelos distintos para a resistência aos enfezamentos. A explicação é que, quando esses genitores foram cruzados entre si, provavelmente ocorreu heterose ou uma complementação alélica, ou seja, combinações híbridas e recíprocas desses genitores tornaram-se mais resistentes do que os próprios genitores, indicando aumento na freqüência de alelos favoráveis distintos, porém de efeito aditivo. Essa mesma explicação é válida, quando se têm combinações híbridas e recíprocas em que um dos genitores é resistente e o outro é suscetível. Neste caso, nos dois locais, considerando-se a significância dos quadrados médios da CGC, constatou-se a existência da variabilidade originada de efeitos gênicos aditivos. O componente da variância do quadrado médio da CGC foi bastante superior ao da CEC, o que possibilita inferir que os efeitos aditivos são predominantes na expressão da menor incidência dos sintomas de enfezamentos, isto é, o controle genético da resistência a esta doença é, predominantemente, de efeitos aditivos.

Os índices médios de doença, apresentados pelos genitores e pelas combinações híbridas, foram
$16,13 \%$ e $12,95 \%$, respectivamente (Tabela 4 ). Os valores dos índices de doença variaram de 3,5\% a 42,98\%. Os genitores P 3041 e C 333B apresentaram os menores índices e os genitores $\mathrm{C} 855$ e AG 122 , os maiores índices dos sintomas de enfezamentos. O P 30F80 teve moderado índice de doença. Os genitores $\mathrm{P} 3041$ e C 333B produziram a combinação híbrida com menor índice de sintomas dos enfezamentos.

Os genitores C 333B e P 3041 apresentaram os menores valores negativos e significativos de CGC, e produziram combinações híbridas com as menores médias de incidência $(7,41 \%$ e $11,20 \%$, respectivamente). Isto indica que os genitores com menor CGC produzem combinações híbridas com menores índices de sintomas dos enfezamentos. O C 855 apresentou a maior CGC, nos dois locais, conseqüentemente a média de suas combinações híbridas foi alta (17,52\%). O genitor AG 122 apresentou comportamento distinto, em ambos os locais.

Em relação à severidade, houve efeito significativo para a CGC e não para CEC (Tabela 2). A severidade média apresentada pelos genitores e pelas combinações híbridas foram 3,27 e 3,81, respectivamente (Tabela 4). Os valores da severidade variaram de 2,5 a 5,29. Os genitores P 3041 e C 333B e a combinação híbrida entre eles apresentaram as menores severidades. A severidade média das combinações híbridas, que envolveram os genitores P 3041 e C 333B, foram 3,78 e 3,98, respectivamente. Nos dois locais, os menores valores de CGC foram obtidos com os genitores P 3041 e C 333B, e os maiores valores com o C 855 e AG 122 .

Os genitores P 3041 e C 333B apresentaram os menores valores da CGC para as características de incidência, índice de doença e severidade dos sintomas de enfezamentos, indicando que esses genitores possuem alta concentração de alelos favoráveis à resistência aos enfezamentos. Os genitores C 855 e AG 122 tiveram os maiores valores para a CGC, apresentando alta frequiência de alelos desfavoráveis à resistência aos enfezamentos.

A relação entre os quadrados médios da CGC e CEC, para a incidência, foi 18,16 e 18,3, em Coimbra e Sete Lagoas, respectivamente. Quanto ao índice de doença, a relação entre os quadrados médios da CGC 
e da CEC foi 16,39 em Coimbra e 14,29 em Sete Lagoas. A relação entre os quadrados médios da CGC e da CEC quanto à severidade foi 3,92 nos dois locais. A alta relação entre a CGC e a CEC, quanto às três características, revelou que a resistência é controlada por vários genes com predominância dos efeitos aditivos.

Para os três métodos, a incidência dos sintomas de enfezamentos apresentou a maior herdabilidade $(89,68 \%)$, seguida pelo índice de doença $(87,43 \%)$ e pela severidade $(60,57 \%)$ (Tabela 2$)$. A $h^{2}$ expressa a proporção da variância fenotípica atribuída à causa genética (Cruz \& Regazzi, 1997). Com base na $h^{2}$ encontrada para incidência, é possível inferir, com aproximadamente $90 \%$ da variância fenotípica, que os genitores e as combinações híbridas que apresentaram as menores e as maiores incidências, são os que possuem maior e menor grau de resistência genética aos enfezamentos, respectivamente. Assim, a alta herdabilidade apresentada pela incidência é o método de avaliação mais eficiente para discriminar os níveis de resistência aos enfezamentos no campo. Entretanto, o método baseado na severidade não se mostrou eficiente para discriminar os níveis de resistência aos enfezamentos, por causa da baixa herdabilidade apresentada, ou seja, com base nos sintomas, nem sempre os genitores e as combinações híbridas que apresentam as menores severidades são os que apresentam resistência genética aos enfezamentos. Quanto ao índice de doença, que é a associação entre incidência e severidade, verificouse que $\mathrm{a} \mathrm{h}^{2}$ foi alta, porém apresentou alto CVe (\%), o que indica a pouca confiabilidade deste método, porque ele considera a combinação entre a incidência e a severidade, e esta última mostrou-se pouco eficiente em discriminar os níveis de resistência. Esses resultados corroboram os de Oliveira, E. et al. (2002), os quais relataram que a resistência aos enfezamentos é determinada pelo número de plantas infectadas (incidência) e não pelo nível de resistência das plantas infectadas (severidade).

Tabela 4. Médias do índice e da severidade da doença (acima da diagonal), estimativa da capacidade geral de combinação (CGC) e estimativa média da capacidade específica de combinação (CEC) (abaixo da diagonal, entre parênteses), dos genitores e das combinações híbridas e médias das combinações híbridas de milho em Coimbra e Sete Lagoas, MG.

\begin{tabular}{lcccccr}
\hline Genitores & AG 122 & P 3041 & P 30F80 & C 333B & C 855 & Média \\
\hline & \multicolumn{5}{c}{ Índice de doença } \\
AG 122 & 21,53 & 11,17 & 19,90 & 7,38 & 20,46 & 14,73 \\
P 3041 & $(-1,01)$ & 3,50 & 10,66 & 4,71 & 18,25 & 11,20 \\
P 30F80 & $(4,46)$ & $(1,65)$ & 9,05 & 5,58 & 19,37 & 13,88 \\
C 333B & $(-1,70)$ & $(2,07)$ & $(-0,32)$ & 3,57 & 11,97 & 7,41 \\
C 855 & $(-4,67)$ & $(-0,45)$ & $(-2,58)$ & $(-3,62)$ & 42,98 & 17,52 \\
\hline CGC (Coimbra) & $-0,711$ & $-2,355$ & $-0,882$ & $-6,272$ & 10,219 & 7,870 \\
\hline CGC (Sete Lagoas) & 5,760 & $-5,460$ & $-0,420$ & $-7,750$ & & 3,96 \\
& & & Severidade da doença & & 3,78 \\
AG 122 & 3,75 & 3,92 & 4,17 & 3,75 & 4,00 & 3,37 \\
P 3041 & $(0,19)$ & 2,50 & 4,08 & 3,08 & 4,05 & 3,98 \\
P 30F80 & $(0,15)$ & $(0,48)$ & 3,25 & 5,29 & 3,96 & 3,95 \\
C 333B & $(0,23)$ & $(-0,03)$ & $(0,22)$ & 2,33 & 3,79 & 4,50 \\
C 855 & $(-0,19)$ & $(0,17)$ & $(-0,20)$ & $(0,13)$ & 0,34 & \\
\hline CGC & 0,20 & $-0,21$ & 0,08 & $-0,42$ & 0,43 & \\
\hline
\end{tabular}




\section{Conclusões}

1. O controle genético da resistência aos enfezamentos do milho é predominantemente de alelos de efeitos aditivos.

2. Os genitores diferem quanto à freqüência de alelos aditivos e não-aditivos em relação à resistência aos enfezamentos.

3. Os genitores $\mathrm{P} 3041$ e C 333B possuem alta freqüência de alelos distintos, que conferem a resistência aos enfezamentos do milho.

4. O método baseado na incidência dos sintomas de enfezamentos é o mais eficiente para discriminar os níveis de resistência aos enfezamentos do milho no campo.

5. Não há diferença entre recíprocos para incidência, índice de doença, severidade dos sintomas de enfezamentos do milho e produtividade de grãos.

\section{Referências}

BARROS, T. S. L.; DAVIS, R. E.; RESENDE, R. O. Design of a polymerase chain reaction for specific detection of corn stunt spiroplasma, Spiroplasma kunkelii. Plant Disease, St. Paul, v. 85, p. 475-480, 2001.

BASSO, M. C. Síntese de compostos de milho (Zea mays $\mathrm{L}$.) com resistência ao complexo de enfezamento. 1999. 122 f. Tese (Doutorado em Genética e Melhoramento de Plantas) - Escola Superior de Agricultura Luiz de Queiroz, Piracicaba, 1999.

CRUZ, C. D. Programa Genes: versão Windows: aplicativo computacional em genética e estatística. Viçosa, MG: Imprensa Universitária, 2001. 648 p.

CRUZ, C. D.; REGAZZI, A. J. Modelos biométricos aplicados ao melhoramento genético. 2. ed. Viçosa, MG: Imprensa Universitária, 1997. 390 p.

FANCELLI, A. L.; DOURADO-NETO, D. Produção de milho. Guaíba: Agropecuária, 2000. 360 p.

GRIFFING, B. Concept of general and specific combining ability in relation to diallel crossing systems. Australian Journal of Biological Sciences, Collingwood, v. 9, p. 463493, 1956.

GROGAN, C. O.; ROSENKRANZ, E. E. Genetic of host reaction to corn stunt virus. Crop Science, Madison, v. 8, p. 251-254, 1968.

LEE, I. M.; HAMMONS, R. W.; DAVIS, R. E.; GUNDERSEN, D. E. Universal amplification and analysis of pathogen 16S rDNA for classification and identification of mycoplasmalike organisms. Phytopathology, St. Paul, v. 83, n. 8, p. 834-842, 1993.
MÁRQUEZ SÁNCHEZ, F. The genetic improvement of resistance to the maize disease stunt and downy mildew in Nicaragua. Revista Chapingo, México, v. 7, n. 35/36, p. 2627, 1982.

NAULT, L. R. Maize bushy stunt and corn stunt: a comparison of disease symptoms, pathogen host ranges, and vectors. Phytopathology, St. Paul, v. 70, n. 7, p. 659$662,1980$.

NELSON, L. R.; SCOTT, G. E. Diallel analysis of resistance of corn (Zea mays L.) to corn stunt. Crop Science, Madison, v. 13, n. 2, p. 162-164, Mar./Apr. 1973.

OLIVEIRA, C. M.; MOLINA, R. M. S.; ALBRES, R. S.; LOPES, J. R. S. Disseminação de molicutes do milho a longas distâncias por Dalbulus maidis (Hemiptera: Cicadellidae). Fitopatologia Brasileira, Brasília, v. 27, p. 91-95, 2002.

OLIVEIRA, E.; OLIVEIRA, C. M.; SOUZA, I. R. P.; MAGALHÃES, P. C.; CRUZ, I. Enfezamentos em milho: expressão de sintomas foliares, detecção dos molicutes e interações com genótipos. Revista Brasileira de Milho e Sorgo, Sete Lagoas, v. 1, n. 1, p. 53-62, jan./abr. 2002.

OLIVEIRA, E.; WAQUIL, J. M.; FERNANDES, F. T.; PAIVA, E.; RESENDE, R. O.; KITAJIMA, E. W. Enfezamento pálido e enfezamento vermelho na cultura do milho no Brasil Central. Fitopatologia Brasileira, Brasília, v. 23 , n. 1 , p. 45-47, mar. 1998.

PINTO, N. F. J. A.; FERNANDES, F. T.; OLIVEIRA, E. Controle de doenças do milho. In: VALE, F. X. R.; ZAMBOLIM, L. (Ed.). Controle de doenças de plantas: grandes culturas. Viçosa, MG: Imprensa Universitária, UFV, 1997. v. 2, p. 821-864.

SILVA, R. G. Fontes de resistência e controle genético dos enfezamentos do milho. 2002. 52 f. Dissertação (Mestrado em Fitotecnia) - Universidade Federal de Viçosa, Viçosa, MG, 2002.

SILVA, R. G; GALVÃO, J. C. C.; MIRANDA, G. V.; SILVA, E. do C.; CORRÊA, L. A. Flutuação populacional de Dalbulus maidis (DeLong \& Wolcott, 1923) (Hemiptera: Cicadellidae) e avaliação de sintomas do complexo enfezamento em híbridos de milho. Revista Ciência e Agrotecnologia, Lavras, v. 26, n. 2, p. 292-300, mar./abr. 2002.

TANAKA, M. A. S. Patogenicidade e transmissão por semente do agente causal da ramulose do algodoeiro. 1990. $111 \mathrm{f}$. Tese (Doutorado em Fitopatologia) - Escola Superior de Agricultura Luiz de Queiroz, Piracicaba, 1990.

WAQUIL, J. M.; FERNANDES, F. T. Flutuação populacional da cigarrinha do milho $D$. maidis, no CNPMS. In: EMBRAPA. Centro Nacional de Pesquisa de Milho e Sorgo (Sete Lagoas, MG). Relatório técnico anual do Centro Nacional de Pesquisa de Milho e Sorgo, 19921993. Sete Lagoas, 1994. p. 68-74. 